\title{
Comparação das técnicas de ELISA indireto e Imunofluorescência indireta na detecção de anticorpos anti-Neospora caninum em búfalas (Bubalus bubalis) ${ }^{1}$
}

\author{
Sandro P. Silva ${ }^{2 *}$, Rinaldo A. Mota ${ }^{3}$, Eduardo B. Faria ${ }^{3}$, Alexandre R. Casseb ${ }^{4}$, \\ Livia M.N. Casseb ${ }^{5}$ e Hilma L.T. Dias ${ }^{2}$
}

\begin{abstract}
Silva S.P., Mota R.A., Faria E.B., Casseb A.R., Casseb L.M.N. \& Dias H.L.T. 2013. [Comparison of indirect ELISA and indirect immunofluorescence in detection of antibodies to Neospora caninum in buffaloes (Bubalus bubalis).] Comparação das técnicas de ELISA indireto e Imunofluorescência indireta na detecção de anticorpos anti-Neospora caninum em búfalas (Bubalus bubalis). Pesquisa Veterinária Brasileira 33(4):431-434. Laboratório de Investigação e Diagnóstico de Enfermidades Animais, Universidade Federal do Pará, Belém, PA, Brazil. E-mail: spatroca@yahoo.com.br

To compare two serologic tests for detection of antibodies against Neospora caninum in sera from buffaloes, samples were collected from 288 buffaloes of 2 to 10 years of age. To identify the presence of IgG, anti- $N$. caninum was used for the indirect immunofluorescence assay (IFAT), with title 200 as the cutoff, and for the immunoenzymatic test (indirect ELISA), considering as positive samples with ratio $\mathrm{S} / \mathrm{P} \geq 0.5$. There were $153(53.12 \%)$ animals positive for $N$. caninum by IFAT, whilst 50 (17.36\%) animals were reactive in ELISA. The presence of antibodies anti- $N$. caninum demonstrates that the parasite is circulating among buffaloes raised in Pará State, Brazil. ELISA and IFAT tests could be used to diagnose immunoglobulins against this agent. However there was a weak correlation (Kappa $=0.36$ ) between both tests, considering the IFAT as the gold standard.
\end{abstract}

INDEX TERMS: Neospora caninum, serology, buffaloes, IFAT, ELISA.

RESUMO.- Para comparar dois testes sorológicos na detecção de anticorpos anti-Neospora caninum em soros sanguíneos de búfalas, foram coletados amostras de 288 búfalas entre dois a dez anos de idade. Para identificar a presença de imunoglobulina $\mathrm{G}$ anti- $N$. caninum utilizou-se à reação de imunofluorescência indireta (RIFI), tendo o título 200 como ponto de corte, e o Ensaio Imunoenzimático indi-

\footnotetext{
${ }^{1}$ Recebido em 8 de janeiro de 2013.

Aceito para publicação em 15 de fevereiro de 2013.

${ }^{2}$ Laboratório de Investigação e Diagnóstico de Enfermidades Animais, Instituto de Ciências Biológicas, Universidade Federal do Pará (UFPA), Rua Augusto Corrêa 1, Guamá, Cx. Postal 479, Belém, PA 66075-110, Brasil. *Autor para correspondência: spatroca@yahoo.com.br

${ }^{3}$ Laboratório de Bacterioses, Departamento de Medicina Veterinária, Universidade Federal Rural de Pernambuco (UFRPE), Rua Dom Manoel de Medeiros s/n, Dois Irmãos, Recife, PE 52171-900, Brasil.

${ }^{4}$ Instituto da Saúde e Produção Animal, Laboratório de Imunologia e Microbiologia, Universidade Federal Rural da Amazônia (UFRA), Av. Presidente Tancredo Neves 250, Bairro Montese, Belém, PA 66077-901. E-mail: alexcasseb@yahoo.com.br

${ }^{5}$ Pesquisadora do Instituto Evandro Chagas, Rodovia BR-316 s/n, Bairro Levilândia, Ananindeua, PA 67030-000, Brasil. E-mail: liviacasseb@iec.pa.gov.br
}

reto (ELISA-indireto), considerando-se positiva as amostras que obtiveram razão $S / P \geq 0,5$. Observaram-se 153 $(53,12 \%)$ animais soropositivos para $N$. caninum, através da RIFI, enquanto que $50(17,36 \%)$ animais foram reagentes no ELISA. A ocorrência de anticorpos anti- $N$. caninum demonstram que o parasito esta circulando entre búfalas criadas no estado do Pará, sendo que ambos os teste de RIFI e ELISA podem ser utilizados para diagnosticar imunoglobulinas contra este agente. No entanto observou-se uma fraca correlação (Kappa=0,36) entre ambos os testes, considerando a RIFI como padrão ouro.

TERMOS DE INDEXAÇÃO: Neospora caninum, sorologia, búfalos, RIFI, ELISA.

\section{INTRODUÇÃO}

A neosporose é uma enfermidade contagiosa causada por Neospora caninum, um protozoário formador de cistos em tecidos de animais, tendo como hospedeiro definitivo o cão. Até 1988 era confundido com Toxoplasma gondii, devido as suas estruturas similares, porém os agentes são distintos em sua ultra-estrutura, imunogenicidade e pato- 
genicidade ao hospedeiro (Dubey et al. 1988, Ragozo et al. 2003).

N. caninum apresenta distribuição mundial, sendo considerado um importante causador de abortamento em bovinos, no entanto, pouco se sabe sobre esta patologia em bubalinos (Dubey et al. 1998, Dubey \& Schares, 2006).

Estudos sorológicos realizados no Egito (Dubey et al. 1998), Vietnã (Huong et al. 1998) e Itália (Guarino et al. 2000) demonstraram a presença de anticorpos contra $N$. caninum, sugerindo a presença deste agente em seus rebanhos de búfalos.

Trabalhos realizados no Brasil identificaram a presença de anticorpos anti- $N$. caninum em bubalinos nos estados de São Paulo (Fujii et al. 2001, Souza et al. 2001, Rodrigues et al. 2005) e Bahia (Gondim et al. 1999, Gondim et al. 2007).

No Pará, estudos realizados por Gennari et al. (2005) demonstraram ocorrência de 70,\% nas 196 búfalas testadas, provenientes de três propriedades rurais, onde todas apresentaram animais positivos para N. caninum.

Devido a importância da bubalinocultura para o estado do Pará e a escassez de trabalhos envolvendo essa espécie, objetivou-se estudar a ocorrência de anticorpos IgG anti- $N$. caninum em búfalas criadas nesse Estado, além de realizar um estudo comparativo entre a Reação de imunofluorescência indireta (RIFI) e o Ensaio imunoenzimático (ELISA) na detecção de animais soropositivos

\section{MATERIAL E MÉTODOS}

$\mathrm{Na}$ presente pesquisa foram coletadas, por conveniência, 288 amostras de soro sanguíneo de fêmeas com idade entre dois a dez anos, das raças Murrah, Mediterrâneo, Carabao, Jafarabadi e mestiços, em 14 propriedades rurais pertencentes a 13 municípios do estado do Pará (Quadro 1).

Após contenção dos animais realizou-se a punção da veia jugular e o sangue coletado foi acondicionado em tubos de vidro estéreis devidamente identificados e mantidos em temperatura ambiente para posterior centrifugação e obtenção do soro. Os soros sanguíneos foram estocados em microtubos de polipropileno previamente identificados e mantidos congelados a $-20^{\circ} \mathrm{C}$ até o momento da realização das provas sorológicas.
A Reação de Imunofluorescência Indireta (RIFI) foi realizada no Laboratório de Bacterioses do Departamento de Medicina Veterinária da Universidade Federal Rural de Pernambuco - UFRPE, seguindo protocolo descrito por Souza et al. (2001) para pesquisa de imunoglobulinas G anti-N. caninum, considerando o título 200 como ponto de corte.

No diagnóstico sorológico através da RIFI, utilizaram-se taquizoítos da cepa NC-1 obtidos na cultura in vitro em células VERO. Foram utilizados soros controle positivo e negativo para $N$. caninum previamente conhecidos, assim como conjugado anti-IgG bovino (molécula inteira com FITC, produzido em coelhos Sigma/F-7887).

As amostras foram submetidas a diluições seriadas de razão dois até a obtenção da maior diluição positiva na RIFI. A leitura foi realizada em microscópio de fluorescência com aumento de 400x. Foi considerada como reação positiva a fluorescência periférica total dos taquizoítos. 0 título do soro foi a recíproca da maior diluição que apresentou resultado positivo.

Em outra momento utilizou-se o Ensaio Imunoenzimático (ELISA) para identificar a presença de anticorpos IgG anti- $N$. caninum, sendo o mesmo realizado no Laboratório de Investigação e Diagnóstico de Enfermidades Animais (LIDEA) da Universidade Federal do Pará (UFPA), utilizando-se kit comercial HerdChek anti-Neospora caninum (IDEXX Laboratories, Inc., Westbrook, Maine, USA).

Todas as 288 amostras foram inicialmente diluídas em 1:100 e processadas de acordo com as especificações apresentadas no kit. A densidade óptica (D.O.) foi mensurada utilizando o filtro de $630 \mathrm{~nm}$. As amostras de soro com razão S/P (sample/positive) $\geq 0,5$ foram consideradas positivas.

A diferença do percentual de infecção entre as propriedades foi verificada pelo teste do Qui-quadrado $\left(X^{2}\right)$, tendo nível alfa de 0,05 . A concordância entre os teste foi obtida com base no coeficiente Kappa. Os valores de sensibilidade e especificidade também foram calculados. Todos os resultados foram tratados estatisticamente pelo software BioEstat 5.0(Ayres et al. 2007).

\section{RESULTADOS}

Do total de 288 amostras analisadas pela RIFI, 153 $(53,12 \%)$ foram positivas para IgG anti- $N$. caninum e 135 $(46,88 \%)$ foram negativas. Os títulos de anticorpos nas 153 búfalas positivas foram $200(40,52 \%), 400(22,88 \%), 800$ (20,92\%), 1600 (9,15\%) e 3200 (6,54\%) (Quadro 1).

Quadro 1. Comparação de resultados obtidos na RIFI e no ELISA indireto para anticorpos anti-Neospora caninum por fazendas estado do Pará, 2008

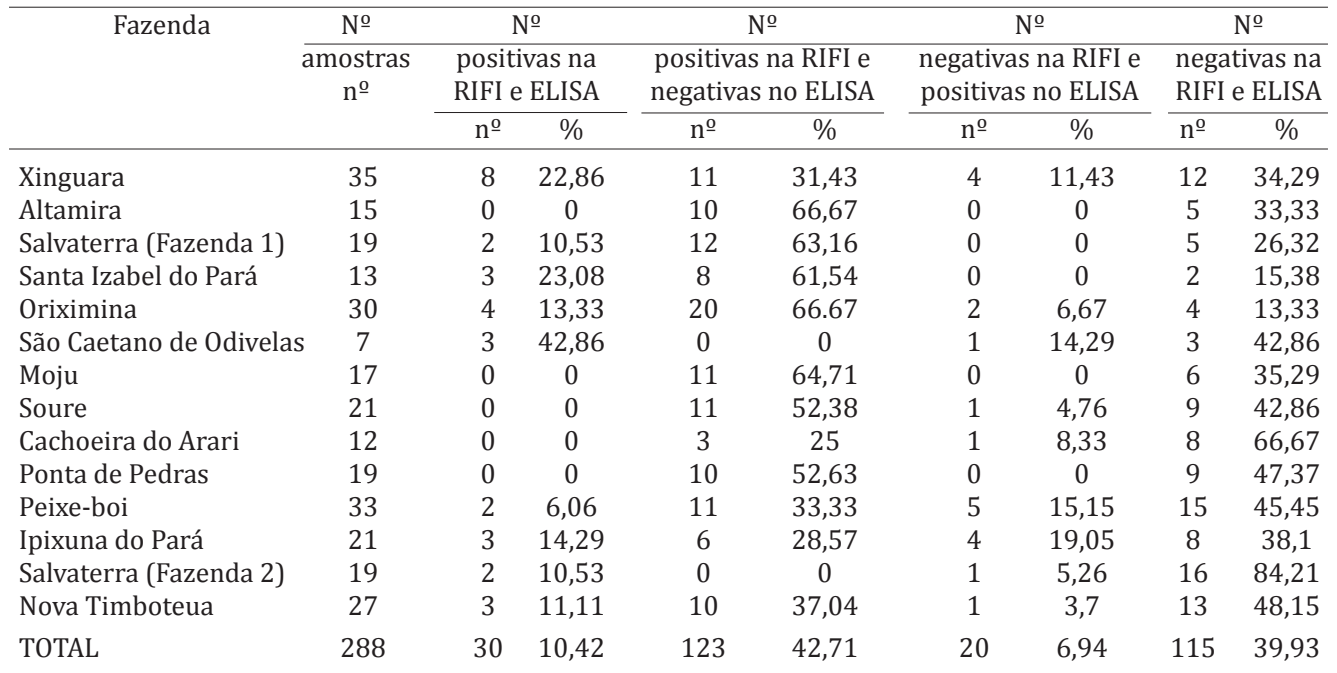


Em relação às propriedades obteve-se $100 \%$ dos rebanhos analisados positivos, uma vez que todas as 14 fazendas apresentaram pelo menos um animal positivo com frequência variando de 8 a 84,62\%, sendo que as mesmas apresentaram diferença significativa $(p<0,05)$ quando comparadas entre si.

No ELISA comercial observou-se que das 288 amostras analisadas, $50(17,36 \%)$ foram positivas e $238(82,64 \%)$ negativas (Quadro 1).

Nas 14 propriedades analisadas, 12 apresentaram pelo menos um animal positivo. A frequência de rebanhos positivos foi de $85,71 \%$, onde algumas propriedades obtiveram valor de $p<0,05$, caracterizando diferença significativa entre os resultados observados.

De acordo com os dados do Quadro 2, a porcentagem de concordância dos resultados positivos nas provas de RIFI e ELISA foi de $19,6 \%(a / a+b)$ enquanto que $85,1 \%(d / c+d)$ foram a porcentagem de concordância dos resultados negativos, totalizando uma porcentagem de concordância de $50,36 \%(a+d / a+b+c+d)$. O ELISA mostrou uma fraca concordância com a RIFI (Kappa $=0,36)$, e resultados comparativos do teste de ELISA com a RIFI sendo padrão ouro, apresentaram 19.61 e $85.19 \%$ de sensibilidade e especificidade, respectivamente, no ELISA.

\section{Quadro 2. Distribuição dos soros de búfalas de acordo com os resultados das provas de RIFI e ELISA para pesquisa de anticorpos anti-Neospora caninum}

\begin{tabular}{ccccc}
\hline & & \multicolumn{2}{c}{ RIFI } & Total \\
\cline { 3 - 4 } & & Positivo & Negativo & \\
\hline \multirow{2}{*}{ ELISA } & Positivo & $30(\mathrm{a})$ & $20(\mathrm{~b})$ & $50(\mathrm{a}+\mathrm{b})$ \\
& Negativo & $123(\mathrm{c})$ & $115(\mathrm{~d})$ & $238(\mathrm{c}+\mathrm{d})$ \\
\multirow{2}{*}{ TOTAL } & & $153(\mathrm{a}+\mathrm{c})$ & $135(\mathrm{~b}+\mathrm{d})$ & $288(\mathrm{a}+\mathrm{b}+\mathrm{c}+\mathrm{d})$
\end{tabular}

\section{DISCUSSÃO}

No que se refere a anticorpos IgG anti-Neospora caninum, valores inferiores foram descritos na Itália com 34,6\%; no Brasil com 36,5\% e 35,9\%, ambos na Bahia, de búfalos positivos (Gondim et al. 1999, Guarino et al. 2000, Gondim et al. 2007). Valores semelhantes foram observados por Souza et al. (2001) verificaram $56,0 \%$ de positividade. Percentuais mais elevados foram descritos no Egito com soroprevalência de 68\%; na Argentina com uma frequência de 64\%; e no Brasil com soroprevalência de 64\% e 79\%, ambos em São Paulo, e 70,9\% no Pará (Dubey et al. 1998, Fujii et al. 2001, Gennari et al. 2005, Rodrigues et al. 2005, Campero et al. 2007).

Neste estudo, 53 búfalas $(16,82 \%)$ foram positivas no ELISA, resultado este maior ao descrito por Huong et al. (1998) no Vietnam, onde três búfalas $(1,5 \%)$ foram reagentes através do ELISA, e confirmadas posteriormente pela RIFI.

Diversos testes sorológicos vêm sendo usados no diagnóstico da neosporose, incluindo a Reação de Imunofluorescência Indireta (RIFI), Ensaio Imunoenzimático Indireto (ELISA) e o Imunoblot, porém a RIFI e o ELISA são mais frequentemente utilizados, por serem relativamente mais baratos (Romero \& Frankena 2004).

Como os taquizoítos utilizados para antígeno nos testes de RIFI estão intactos, o teste detecta principalmente anti- corpos direcionados para antígenos presentes na superfície celular do parasita. Estes são considerados mais específicos que os componentes intracelulares (Trees et al. 1993).

A RIFI foi o primeiro teste sorológico utilizado para detecção de anticorpos anti- $N$. caninum, e apresenta uma boa sensibilidade e especificidade, por isso ele é considerado um teste de referência (padrão ouro), sendo frequentemente comparado com outros testes (Bjorkman \& Uggla, 1999). Entretanto Dubey (2003) afirma que esta técnica não apresenta um ponto de corte definitivo, que se justifica pela incerteza do diagnóstico sorológico em animais cronicamente infectados e da viabilidade dos soros testados.

0 diagnóstico da neosporose, em bovinos, pode ser realizado pela técnica de ELISA, que possui uma maior especificidade e sensibilidade no diagnóstico sorológico de vacas infectadas com N. caninum quando comparado com a RIFI (Bjorkman et al. 1997). E segundo Sartor et al. (2003), um fator favorável para isso, consiste na automação existente na técnica de ELISA que praticamente elimina a interferência técnica, a qual é responsável por erros como, por exemplo, os de leitura de uma lâmina. Entretanto, não existem testes de ELISA, que identifique anticorpos anti- $N$. caninum, padronizados para bubalinos, sendo neste caso utilizados kits com conjugado de bovino.

Em ambas as provas, RIFI e ELISA, houve uma concordância com 30 búfalas reagentes, demonstrando a capacidade dos testes de detectar animais realmente positivos e 115 búfalas não reagentes, demonstrando a capacidade de detectar animais realmente negativos.

Por outro lado, 123 búfalas foram positivas na RIFI e negativas no ELISA. Isso pode ser justificado levando em consideração a maior especificidade do ELISA comparado a RIFI, devido ao fato do ELISA trabalhar com partículas fracionadas dos taquizoítos de $N$. caninum (epítopos ou determinantes antigênicos), diferente da RIFI que utiliza taquizoítos íntegros (Bjorkman et al. 1997, Schares et al. 2005). No entanto, esta concordância foi fraca devido ao grande número de animais falso negativos no ELISA.

Em outra observação, 20 búfalas foram negativas na RIFI, porém positivas no ELISA, isso pode ter ocorrido devido à capacidade do ELISA de detectar quantidades menores de imunoglobulinas, sendo que Locatelli-Dittrich et al. (2001), utilizando o mesmo ELISA comercial da presente pesquisa, encontraram 60 bovinos positivos no ELISA e na RIFI, porém utilizando uma diluição inicial baixa (1:25) e os autores observaram também que a correlação da positividade diminuía na diluição de 1:200, apresentando assim 42 animais positivos em ambas as provas.

Segundo Sartor et al. (2003), durante interpretação dos resultados, deve ser levado em consideração o espaço de tempo decorrido entre o abortamento e a coleta do sangue. Este fato é justificado pela queda de persistência nos títulos da RIFI após o abortamento.

Neste trabalho a sensibilidade do ELISA foi de 19,61\%, valor bem inferior aos apresentados por Venturini et al. (1999) e Sartor et al. (2003), entretanto em ambos os trabalhos essa comparação foi realizada em soro bovino.

O ELISA mostrou uma fraca concordância com a RIFI $($ Kappa $=0,36)$, sendo que essa discordância de resultados 
obtida na RIFI e no ELISA pode ter ocorrido devido à diferença no tipo de anticorpos mensurada nestes testes (Venturini et al. 1999).

Outra possibilidade seria a diferença de conjugado utilizado no kit de ELISA específico para bovinos, que foi utilizado no diagnóstico em soro bubalino. De acordo com Cortez et al. (2001), interações não imunológicas (ruídos decorrentes da adsorção de IgG de búfalos ou de conjugado anti-IgG bovina a microplaca) pode interferir na eficácia destes testes.

Apesar da semelhança entre imunoglobulinas de ambas as espécies, a resposta imune de búfalos e bovinos podem ser diferentes em intensidade, duração ou desenvolvimento (Corrêa 2007).

\section{CONCLUSÕES}

A identificação de anticorpos IgG contra Neospora caninum é um indicativo da presença deste agente em rebanhos bubalinos no Estado do Pará, e pode estar relacionado a perdas econômicas devido à possibilidade de ocasionar abortamentos nestes animais. Neste panorama é importante a utilização de técnicas sorológicas que demonstrem a presença de animais positivos para a neosporose.

Diante deste contexto, a RIFI apresentou maior sensibilidade quando comparado com o ELISA, sendo que este último não seria recomendado para programas sanitários contra esta enfermidade devido a sua baixa sensibilidade nestes animais.

\section{REFERÊNCIAS}

Ayres M., Ayres J.R.M., Ayres D.L. \& Santos A.S. 2007. BioEstat 5.0-Aplicações Estatísticas nas Áreas das Ciências Biológicas e Médicas. Sociedade Civil Mamirauá, Belém. CNPq, Brasília. 290p.

Bjorkman C., Holmdahl O.J.M. \& Uggla A. 1997. An indirect enzyme-linked immunoassay (ELISA) for demonstration of antibodies to Neospora caninum in serum and milk of cattle. Vet. Parasitol. 68:251-260.

Campero C.M., Pérez A., Moore D.P., Crudeli G., Benitez D., Draghi M.G., Cano D., Konrad J.L. \& Odeón A.C. 2007. Occurrence of antibodies against Neospora caninum in water buffaloes (Bubalus bubalis) on four ranches in Corrientes province, Argentina. Vet. Parasitol. 150:155-158.

Corrêa F.N. 2007. Pesquisa de anticorpos homólogos anti-Borrelia burgdorferi em búfalos (Bubalus bubalis) do estado do Pará. Dissertação de Mestrado em Ciência Animal, Universidade Federal Rural do Rio de Janeiro, Seropédica, RJ. 36p.

Cortez A., Heinemann M.B., Alfieri A.A., Médici K.C., Alfieri A.F., Oliveira D.B., Meyer A.D., Soares R.M., Sakamoto S.M., Amaral R., Baruselli P.S., Fuji T. \& Richtzenhain L.J. 2001. Comparação das técnicas de ELISA indireto e de soroneutralização na detecção de anticorpos contra o BHV-1 em amostras de soro bubalino (Bubalus bubalis). Braz. J. Vet. Res. Anim. Sci. 38:146-148.

Dubey J.P., Carpenter J.L., Speer C.A., Topper M.J. \& Uggla A. 1988. Newly recognized fatal protozoan disease of dogs. J. Am. Vet. Med. Assoc. 192:1269-1285.
Dubey J.P. \& Schares G. 2006. Diagnosis of bovine neosporosis. Vet. Parasitol. 140:1-34.

Dubey J.P., Romand S., Hilali M., Kwok O.C.H. \& Thulliez P. 1998. Seroprevalence of antibodies to Neospora caninum and Toxoplasma gondii in water buffaloes (Bubalus bubalis) from Egypt. Int. J. Parasitol. 28:527-529.

Dubey J.P. 2003. Review of Neospora caninum and neosporosis in animals. Korean J. Parasitol. 41:1-16.

Fujii T.U., Kasai N., Vasconcellos S.A., Richtzenhain L.J., Cortez A., Souza S.L.P., Baruselli P.S., Nishi S.M., Ferreira F. \& Gennari S.M. 2001. Anticorpos anti-Neospora caninum e contra outros agentes de abortamentos em búfalas da região do Vale do Ribeira, São Paulo, Brasil. Arqs Inst. Biológico, São Paulo, 68:5-9.

Gennari S.M., Rodrigues A.A.R., Viana R.B. \& Cardoso E.C. 2005. Occurrence of anti-Neospora caninum antibodies in water buffaloes (Bubalus bubalis) from the Northern region of Brazil. Vet. Parasitol. 134:169-171.

Gondim L.F.P., Barbosa Jr H.V., Ribeiro Filho C.H.A. \& Saeki H. 1999. Serological survey of antibodies to Toxoplasma gondii in goats, sheep, cattle and water buffaloes in Bahia State, Brazil. Vet. Parasitol. 82:273-276.

Gondim L.F.P., Pinheiro A.M. \& Almeida M.A.O. 2007. Frequência de anticorpos anti-Neospora caninum em búfalos (Bubalus bubalis) criados no estado da Bahia. Revta Bras. Saúde Prod. Anim. 8:92-96.

Guarino A., Fusco G., Savini G., Francesco G. \& Cringoli G. 2000. Neosporosis in water buffalo (Bubalus bubalis) in southern Italy. Vet. Parasitol. 91:15-21.

Huong L.T.T., Ljungstrom B.L.L., Uggla A. \& Bjorkman C. 1998. Prevalence of antibodies to Neospora caninum and Toxoplasma gondii in cattle and buffaloes in southern Vietnam. Vet. Parasitol. 75:53-57.

Locatelli-Dittrich R., Soccol V.T., Richartz R.R.T.B., Gasino-Joineau M.E., Vinne R. \& Pinckney R.D. 2001. Serological diagnosis of Neosporosis in a herd of dairy cattle in southern Brazil. J. Parasitol. 87:1493-1494.

Ragozo A.M.A., Paula V.S.O., Souza S.L.P., Bergamaschi D.P. \& Gennari S.M. 2003. Ocorrência de anticorpos anti-Neospora caninum em soros bovinos procedentes de seis estados brasileiros. Revta Bras. Parasitol. Vet. 12:33-37.

Rodrigues A.A.R., Gennari S.M., Paula V.S.O., Aguiar D.M., Fujii T.U., Starke-buzeti W., Machado R.Z. \& Dubey J.P. 2005. Serological responses to Neospora caninum in experimentally and naturally infected water buffaloes (Bubalus bubalis). Vet. Parasitol. 129:21-24.

Romero J.J. \& Frankena K. 2004. Bovine neosporosis: a review. Journal of Animal and Veterinary Advances. 3:901-913.

Sartor I.F., Hasegawa M.Y., Canavessi A.M.O. \& Pinckney R.D. 2003. Ocorrência de anticorpos de Neospora caninum em vacas leiteiras avaliados pelos métodos ELISA e RIFI no município de Avaré, SP. Ciênc. Agrárias 24:3-10.

Schares G., Barwald A. \& Conraths F.J. 2005. Adaptation of a surface antigen-based ELISA for the detection of antibodies against Neospora caninum in bovine milk. J. Vet. Med. B 52:45-48.

Souza L.M., Nascimento A.A., Furuta P.I., Basso L.M.S., Silveira D.M. \& Costa A.J. 2001. Detecção de anticorpos contra Neospora caninum e Toxoplasma gondii em soros de bubalinos (Bubalus bubalis) no Estado de São Paulo, Brasil. Ciênc. Agrárias 22:39-48.

Trees A.J., Guy F., Tennant B.J., Baufour A.H. \& Dubey J.P. 1993. Prevalence of antibodies to Neospora caninum in a population of urban dogs in England. Vet. Rec. 132:125-126.

Venturini M.C., Venturini L., Bacigalupe D., Machuca M., Echaide I., Basso W., Unzaga J.M., Di lorenzo C., Guglielmone A., Jenkins M.C. \& Dubey J.P. 1999. Neospora caninum infections in bovine foetuses and dairy cows with abortions in Argentina. Int. J. Parasitol. 29:1705-1708. 